\title{
Supersize my brain: A cross-sectional voxel-based morphometry study on the association between self-reported dietary restraint and regional grey matter volumes
}

\author{
Laura N. van der Laan ${ }^{a}, *$, Lisette Charbonnier ${ }^{a}$, Sanne Griffioen-Roose ${ }^{b}$, Floor M. Kroese ${ }^{c}$, \\ Inge van Rijn ${ }^{\mathrm{b}}$, Paul A.M. Smeets ${ }^{\mathrm{a}, \mathrm{b}}$ \\ a Image Sciences Institute, University Medical Center Utrecht, Postal address: Heidelberglaan 100 Q02.4.45, 3584CX Utrecht, The Netherlands \\ ${ }^{\mathrm{b}}$ Division of Human Nutrition, Wageningen University and Research centre, Postal address: PO box 8129, bode 62, 6700 EV Wageningen, The Netherlands \\ ' Department of Clinical and Health Psychology, Utrecht University, Postal address: Padualaan 14, 3584CH Utrecht, The Netherlands
}

\section{A R T I C L E I N F O}

\section{Article history:}

Received 9 June 2015

Received in revised form 2 March 2016

Accepted 14 March 2016

Available online 16 March 2016

\section{Keywords:}

Voxel-based morphometry

Dietary restraint

Grey matter volume

\begin{abstract}
A B S T R A C T
Restrained eaters do not eat less than their unrestrained counterparts. Proposed underlying mechanisms are that restrained eaters are more reward sensitive and that they have worse inhibitory control. Although fMRI studies assessed these mechanisms, it is unknown how brain anatomy relates to dietary restraint. Voxel-based morphometry was performed on anatomical scans from 155 normal-weight females to investigate how regional grey matter volume correlates with restraint. A positive correlation was found in several areas, including the parahippocampal gyrus, hippocampus, striatum and the amygdala (bilaterally, $\mathrm{p}<0.05$, corrected). A negative correlation was found in several areas, including the inferior frontal gyrus, superior frontal gyrus, supplementary motor area, middle cingulate cortex and precentral gyrus ( $p<0.05$, corrected). That higher restraint relates to higher grey matter volume in reward-related areas and lower grey matter volume in regions involved in inhibition, provides a neuroanatomical underpinning of theories relating restraint to increased reward sensitivity and reduced inhibitory capacity.
\end{abstract}

(c) 2016 Elsevier B.V. All rights reserved.

\section{Introduction}

Dietary restraint refers to the intentional and sustained restriction of food intake for the purposes of weight-loss or weightmaintenance (Herman \& Mack, 1975a). However, in contrast to this formal definition of restrained eating there is ample evidence that self-reported restrained eaters, that is, people who score high on self-report scales of dietary restraint, do not eat less than their unrestrained counterparts (de Witt Huberts, Evers, \& De Ridder, 2013; Stice, Fisher, \& Lowe, 2004; Stice, Cooper, Schoeller, Tappe, \& Lowe, 2007; Stice, Sysko, Roberto, \& Allison, 2010). In fact, Herman \& Mack (1975a) established in the seventies already that self-reported restrained eaters over- rather than under-consume. They also were the first to demonstrate that selfreported restrained eaters break their pattern of food restriction after receiving a preload of food. Many studies have replicated this preload-induced loss of dietary control, often denoted as 'disinhibition effect' since then, although null findings have also emerged

\footnotetext{
* Corresponding author.

E-mail address: nynke@isi.uu.nl (L.N. van der Laan).
}

(Knight \& Boland, 1989; Lowe, 1993; Polivy, Heatherton, \& Herman, 1988; Van Strien, 2000). Furthermore, self-reported restrained eaters are more likely to be overweight (Klesges, Isbell, \& Klesges, 1992; Laessle, Tuschl, Kotthaus, \& Pirke, 1989) and healthy weight self-reported restrained eaters/dieters might even be at increased risk for weight gain and future onset of binge-eating (French, Jeffery, \& Wing, 1994; Klesges et al., 1992; Mann et al., 2007; Stice, Presnell, Shaw, \& Rohde, 2004; Tanofsky-Kraff et al., 2006; Lowe, Doshi, Katterman, \& Feig, 2013).

The evidence outlined above suggests that the self-reported status of being a restrained eater is a marker for someone's intention rather than actual success in restricting food intake. It appears that healthy weight self-reported restrained eaters mainly diet to avoid weight gain instead of to lose weight (Chernyak \& Lowe, 2010). Thus, self-reports of restraint in healthy weight individuals might rather signify perceived difficulties in maintaining current weight and dealing appropriately with everyday food temptations than their actual behavior (Lowe \& Levine, 2005; de Ridder, Adriaanse, Evers, \& Verkes, 2014). Explanations for the divergence between self-reported restrained eaters' intention and behavior has been sought in two possible directions, namely that individuals high in self-reported restraint might have a reduced inhibitory con- 
trol capacity, or an increased sensitivity to food reward (or both) (e.g., Nederkoorn, Van Eijs, \& Jansen, 2004; Papies, Stroebe, \& Aarts, 2007). Although it has repeatedly been shown that people high in self-reported dietary restraint are worse at inhibition (Houben \& Jansen, 2014; Nederkoorn et al., 2004), at least one other studies found the opposite, namely that self-reported restrained eaters were better at inhibiting responses to food cues in a computer task than self-reported unrestrained eaters (Meule, Lukito, Vogele, \& Kubler, 2011). More univocal support exists for the second proposition, that self-reported restrained eaters have an increased sensitivity to food rewards: individuals high (versus low) in selfreported restraint show greater salivary response to the sight and smell of food (Brunstrom, Yates, \& Witcomb, 2004; Klajner, Herman, Polivy, \& Chhabra, 1981; LeGoff \& Spigelman, 1987), they report having stronger cravings for palatable foods (Gendall, Joyce, Sullivan, \& Bulik, 1998; Polivy, Coleman, \& Herman, 2005), they have a stronger implicit preference for palatable foods (Houben, Roefs, \& Jansen, 2010; Houben, Roefs, \& Jansen, 2012), are more likely to overeat in response to the smell, sight or thoughts of palatable food (Fedoroff, Polivy, \& Herman, 2003; Fedoroff, Polivy, \& Herman, 1997; Papies \& Hamstra, 2010), and they have an attentional bias towards palatable energy-rich foods (Forestell, Lau, Gyurovski, Dickter, \& Haque, 2012), especially when pre-exposed to palatable food cues (Papies, Stroebe, \& Aarts, 2008), although null findings have also appeared (e.g., Werthmann et al., 2013).

Functional neuroimaging studies suggest that restrained eaters' behaviorally apparent increased reward response to foods is also reflected in an increased responsiveness of their brain's reward circuitry during both viewing and tasting food (Burger \& Stice, 2011; Coletta et al., 2009; Demos, Kelley, \& Heatherton, 2011; Wagner, Boswell, Kelley, \& Heatherton, 2012): Burger and Stice (2011) found that participants who were higher in self-reported dietary restraint had stronger activation in the right orbitofrontal cortex (OFC) in response to tasting a milkshake. Coletta et al. (2009) showed that the normal drop in rewarding value of food after eating was not observed in self-reported restrained eaters. Instead, when self-reported restrained eaters were sated (compared to hungry) they had stronger activation in brain areas involved in hunger and reward (OFC, insula) in response to food pictures (Coletta et al., 2009). Furthermore, when women high in self-reported restraint consumed a milkshake as preload (compared to water) they showed greater activation in the dorsal striatum in response to pictures of appetizing foods (Demos et al., 2011). Combined, these results suggest that restrained eaters have an increased response in reward related brain regions upon viewing and tasting food, particularly when they are in a sated state.

Although the evidence outlined above suggests that selfreported restrained eaters have altered functional brain responses to food, less is known about the role of more stable - anatomical brain characteristics in restrained eating, such as regional grey matter volume. Regional differences in grey matter volume can provide valuable information about normal and abnormal neuroanatomy, and have been linked to individual differences in general personality traits (DeYoung et al., 2010). It is generally thought that a greater volume of a specific brain structure may signify greater power to carry out specific functions associated with that structure (DeYoung et al., 2010).

To our knowledge, only one earlier study investigated the relation between dietary restraint and regional grey matter volume (Brooks et al., 2011). This study was primarily set up to investigate grey matter volume in two subtypes of anorexia patients and reported no significant relation between dietary restraint scores and regional brain volumes in their healthy control group. However, because variations in brain structure associated with personality characteristics in the healthy range are relatively small, their null-finding might be explained by the low number of healthy control subjects $(n=21)$. Studies on the structural basis of personality characteristics usually include much higher numbers of participants (i.e., 100 subjects or more: DeYoung et al., 2010; Fuentes et al., 2012). In the present study, we aimed to investigate how regional brain volume covaries with level of self-reported dietary restraint in a large population of normal weight females. Investigating this is relevant because it yields insights into the brain characteristics of a population at risk for developing problematic eating behaviors and becoming overweight.

Building on the findings from functional neuroscience studies described above, we hypothesized that regional grey matter volume in brain regions involved in food reward and inhibitory control correlate with level of dietary restraint.

Relating food-related and personality related concepts to anatomical features of the brain can potentially reveal common underlying components and any neural substrates. Such an approach may provide new insights into how eating behavior and different cognitive functions are related to each other and which regions underlie those functions. By identifying the brain regions where grey matter volume covaries with personality or eating behavior, we can build brain-based theories of personality and eating behavior. Knowing how brain differences relate to the expression of different traits and behaviors opens directions for future research in both brain structure and eating behavior.

\section{Materials and methods}

\subsection{Ethics statement}

Data used for the analyses in this article was taken from studies that were approved by the Medical Ethical Committee of either the University Medical Center Utrecht or of Wageningen University. All subjects provided written informed consent.

\subsection{Participants}

The sample consisted of 155 females with a healthy weight (mean age \pm SD: $22.9 \pm 4.0$, range: $18-40$; mean Body Mass Index $(B M I) \pm$ SD: $21.5 \pm 1.7$, range: $18.1-25.2$ ), who participated in seven earlier unrelated studies in our and affiliated labs (six published studies (Charbonnier, van der Laan, Viergever, \& Smeets, 2015; Griffioen-Roose et al., 2014; Smeets, Kroese, Evers, \& De Ridder, 2013; van der Laan, De Ridder, Viergever, \& Smeets, 2012; van der Laan, De Ridder, Charbonnier, Viergever, \& Smeets, 2014; van Rijn, de Graaf, \& Smeets, 2015) and one study in preparation). Selfreported length and height (to calculate BMI) were acquired during the screening phase of the study they participated in. Participant selection for the current study was limited to young adult women because they generally score higher on restraint and because of known gender differences as well in reasons for dieting as in brain anatomy and function (Cahill, 2006; Luders, Gaser, Narr, \& Toga, 2009; Neumark-Sztainer, Sherwood, French, \& Jeffery, 1999; Pingitore, Spring, \& Garfield, 1997). All participants were righthanded, non-smokers and had a stable weight (did not gain or lose $>5 \mathrm{~kg}$ in the past 6 months). All participants were healthy, i.e., they reported having no eating disorder and no neurological, metabolic, endocrine or gastrointestinal disorders. Furthermore, none of the participants had a food allergy or followed a medically prescribed diet. Participants were recruited with posters and flyers at the University Medical Center Utrecht or at Wageningen University and Research centre in The Netherlands.

\subsection{Dietary restraint measurement}

The restrained eating scale of the Dutch Eating Behavior Questionnaire (Van Strien, Frijters, Bergers, \& Defares, 1986) was used 
to assess participants' level of dietary restraint. This scale consists of ten items, for example, "Do you deliberately eat less in order not to become heavier?" The items have a six options format with $1=$ never, 2 = rarely, $3=$ sometimes, $4=$ often, $5=$ usually and $6=$ always. Scores on the ten items were averaged, resulting in a restraint score for each participant. The mean level of dietary restraint in our sample was $2.46(\mathrm{SD}=0.62)$, which is in the 'below average' range for non-obese females, according to the norm tables of the DEBQ (Van Strien et al., 1986). Restraint scores were normally distributed (Shapiro-Wilk statistic $=0.98, p>0.05$ ). The restraint scale had a good internal consistency in our study sample (Cronbach's $\alpha=0.87$ ). For all participants, this questionnaire was administered during the screening phase of the study they participated in.

\subsection{Anatomical MRI acquisition}

Data ( $\mathrm{T}_{1}$-weighted anatomical scans) from two scan sites were used in this study. For 104 participants, MRI scanning was performed on a $3 \mathrm{~T}$ Philips Achieva MRI scanner (Philips Healthcare, Best, The Netherlands), with a 3D gradient echo sequence $\left(\mathrm{TR}=8.4 \mathrm{~ms}, \mathrm{TE}=3.8 \mathrm{~ms}\right.$, flip angle $8^{\circ}, \quad F O V=288 \mathrm{~mm} \times 288$ $\mathrm{mm} \times 175 \mathrm{~mm}$, 175 sagittal slices, voxel size $=1 \times 1 \times 1 \mathrm{~mm}$, total scan duration $=284 \mathrm{~s}$ ). For the other 51 participants, MRI scanning was performed on a $3 \mathrm{~T}$ Siemens Magnetom Verio MRI scanner (Siemens, Erlangen, Germany) with an MPRAGE sequence $\left(\mathrm{TR}=1900 \mathrm{~ms}, \mathrm{TE}=2.26 \mathrm{~ms}\right.$, flip angle $9^{\circ}, \mathrm{FOV}=256 \mathrm{~mm} \times 256$ $\mathrm{mm} \times 192 \mathrm{~mm}$, 192 sagittal slices, voxel size $=1 \times 1 \times 1 \mathrm{~mm}$, total scan duration $=349 \mathrm{~s}$ ).

\subsection{Voxel-based morphometry (VBM) processing}

Structural MRI data were processed and analyzed using the SPM8 software package (Wellcome Department of Imaging Neuroscience, London, United Kingdom) ran with MATLAB R2013A (The Mathworks Inc, Natick, MA). The processing steps were largely based on the suggestions made by Ashburner (2010), which we will summarize below. The $\mathrm{T}_{1}$-weighted scans were segmented into tissue class images of grey matter, white matter, cerebrospinal fluid (CSF), skull, soft tissue outside of the brain, and air outside of the head, with the use of the 'new segment' routine. The DARTEL toolbox (Ashburner, 2007) was used to increase the accuracy of inter-subject alignment by modelling the shape of each brain using millions of parameters ( 3 parameters for each voxel). The DARTEL routine in SPM creates a population average template (DARTEL template space) by the following procedure: first, the average of all the GM and WM tissue class images is calculated to create an initial template. Subsequently, the deformations from this template to the individual tissue class images were computed, and inverses of these deformations were applied to regenerate a new template. This was repeated 6 times, resulting in a final, most accurate (Ashburner, 2010), population average template (in DARTEL template space) which is used in the following steps. In addition to the template, this step also results in a flow field for each subject, which provides information about how each individual grey matter tissue class image should be deformed to fit the population average (DARTEL template space). Next, all images are normalized to MNI space. First, an affine transformation was calculated which maps the population average (DARTEL template space) to MNI space. Subsequently, by using this calculation (DARTEL template space to MNI space) as well as the flow fields from the previous step (participant space to DARTEL template space) all grey matter tissue class images were brought to MNI space. In this step, the spatially normalized segmentations of grey matter were also modulated with the Jacobian determinants from the transformation, in order to adjust for the volume changes resulting from the transformation. Finally, images were smoothed with a 3-D Gaussian filter of $8 \mathrm{~mm}$ full width at half maximum.

\subsection{Statistical analysis}

To investigate how regional grey matter volumes correlate with restraint scores, we entered all 155 smoothed grey matter tissue maps into a multiple regression analysis in SPM with age, BMI, scanner site, and restraint score as covariates. Age and BMI were included to control for possible confounding effects and nuisance (Hu et al., 2011; Taki et al., 2008; Veit et al., 2014). Scanner site was included to control for scanner effects (Stonnington et al., 2008). The intercept was modeled as well. Analyses were corrected for total intracranial volume by global normalization with proportional scaling. Total intracranial volume was obtained by summing up the overall volumes of grey matter, white matter and CSF for each participant.

A statistical threshold of $\mathrm{p}<0.05$ corrected for multiple comparisons across the whole brain was used. This threshold was implemented by means of cluster size correction in AFNI's 3dClustSim module (the successor of AlphaSim; Cox, 1996). 3DClustSim calculates the minimum size of non-noise clusters at a given uncorrected threshold by performing Monte Carlo simulations (5000 iterations) of random noise with the data's voxel size, the number of voxels in the inclusive mask and the inherent smoothness of the data. These simulations indicated that results surviving a threshold of $\mathrm{p}<0.05$ uncorrected, with a cluster extent of $\mathrm{k} \geq 2817$ voxels can be considered significant corrected for multiple comparisons.

\section{Results}

There was a significant positive association between dietary restraint scores and grey matter volumes in several areas (Fig. 1; Table 1), including bilateral clusters in the supramarginal gyrus, bilateral clusters in the middle frontal gyrus, and clusters in the inferior temporal gyrus, precuneus and the rectus/orbital part of the superior frontal gyrus. Furthermore, there was a significant positivecorrelation with dietary restraint in bilateral clusters in the limbic system. The cluster in the left hemisphere includes parts of the dorsal striatum (putamen, pallidum), hippocampus, amygdala, and parahippocampal gyrus. The cluster in the right hemisphere includes parts of the right dorsal striatum (putamen), hippocampus, amygdala and parahippocampal gyrus.

There was a significant negative association between dietary restraint scores and grey matter volume in several areas (Fig. 2; Table 2), including a cluster stretching from the middle/anterior cingulate cortex to the supplementary motor area and the precentral gyrus, and clusters in the temporal pole/insula, cerebellum, paracentral lobule, cuneus, postcentral gyrus/inferior frontal gyrus and precentral gyrus.

\section{Discussion}

Our aim was to investigate how regional brain volumes covary with level of self-reported dietary restraint in normal weight females. In line with our expectations, we found that the degree of self-reported restrained eating was associated positively with regional grey matter volumes in several areas, including areas related to reward-related processing. We found that restraint correlated negatively with regional grey matter volume in several areas, including regions involved in inhibition. Selfreported restraint was correlated positively with a cluster in the orbitofrontal cortex and bilateral clusters in the brain comprising the parahippocampal gyrus, hippocampus, the dorsal striatum (putamen/pallidum) and the amygdala. The orbitofrontal cortex is 

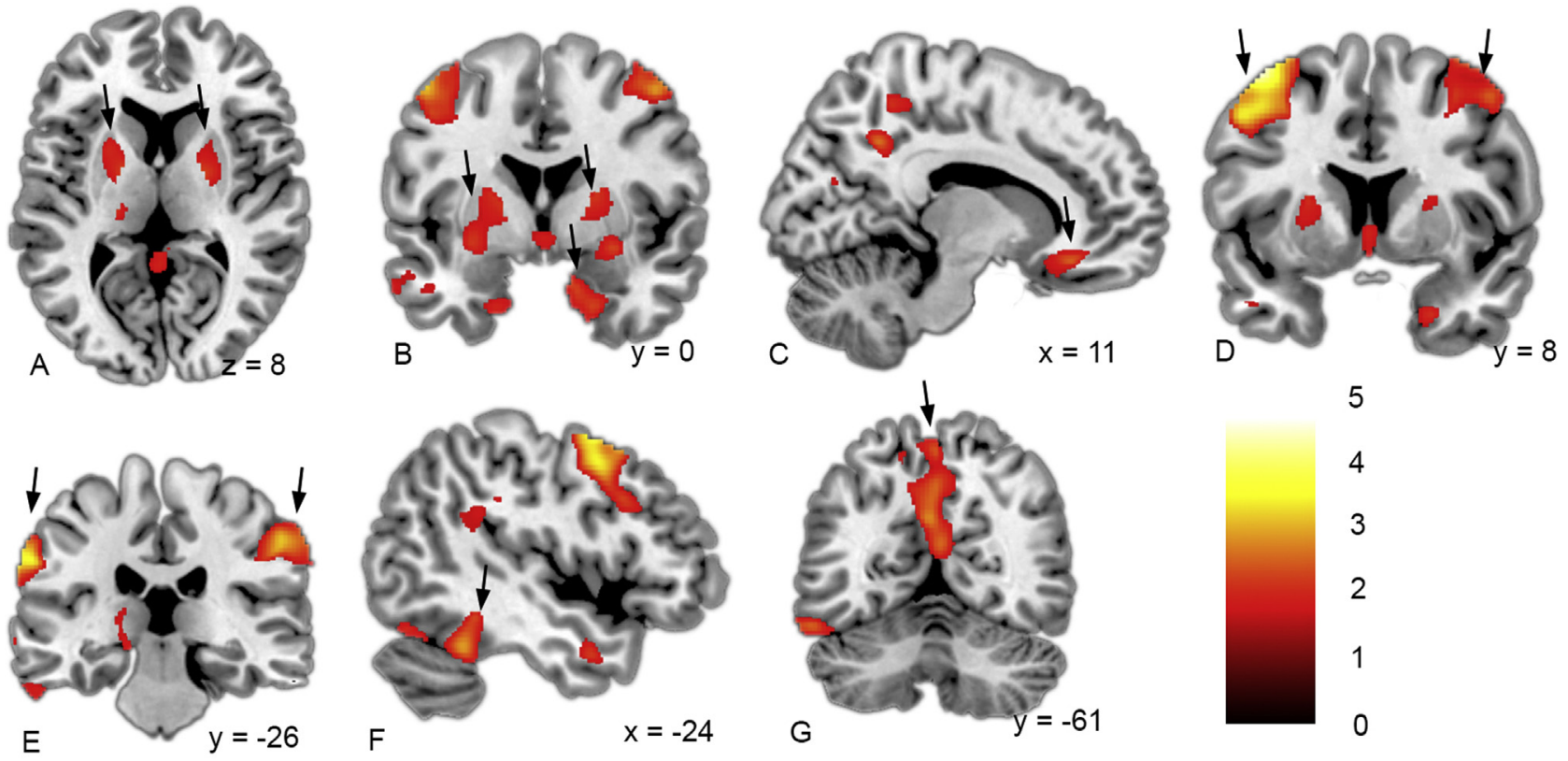

5

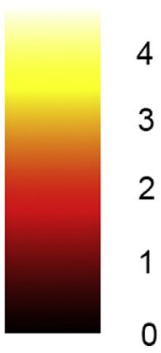

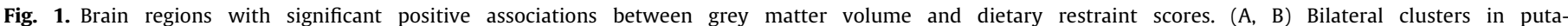

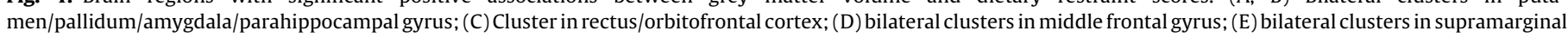
gyrus; (F) cluster in inferior temporal gyrus; $(G)$ cluster in precuneus. VBM results are thresholded at $\mathrm{p}<0.05$ corrected.

Table 1

Brain regions in which regional grey matter volume was significantly ${ }^{1}$ positively associated with restraint scores.

\begin{tabular}{|c|c|c|c|c|c|c|c|}
\hline \multirow[b]{2}{*}{ Brain region } & \multirow[b]{2}{*}{ Side } & \multicolumn{3}{|c|}{ MNI coordinates } & \multicolumn{3}{|l|}{ Cluster } \\
\hline & & $\mathrm{X}$ & Y & $\mathrm{Z}$ & size k & $\mathrm{Z}$ & $\mathrm{T}$ \\
\hline Middle frontal gyrus & $\mathrm{L}$ & -42 & 8 & 60 & 11031 & 4.51 & 4.68 \\
\hline Precentral gyrus/middle frontal gyrus & $\mathrm{L}$ & -52 & 13 & 43 & & 3.99 & 4.10 \\
\hline Precentral gyrus & $\mathrm{L}$ & -48 & 2 & 56 & & 3.63 & 3.72 \\
\hline Supramarginal gyrus & $\mathrm{L}$ & -66 & -30 & 36 & 5065 & 4.38 & 4.53 \\
\hline Supramarginal gyrus & $\mathrm{L}$ & -68 & -37 & 26 & & 2.71 & 2.74 \\
\hline Superior temporal gyrus & $\mathrm{L}$ & -58 & -37 & 20 & & 2.17 & 2.19 \\
\hline Inferior temporal gyrus & $\mathrm{L}$ & -51 & -43 & -25 & 8410 & 3.40 & 3.47 \\
\hline Inferior temporal gyrus & $\mathrm{L}$ & -66 & -11 & -26 & & 3.13 & 3.19 \\
\hline Inferior temporal gyrus & $\mathrm{L}$ & -49 & -41 & -15 & & 2.87 & 2.91 \\
\hline Supramarginal gyrus & $\mathrm{R}$ & 57 & -25 & 42 & 6717 & 3.31 & 3.38 \\
\hline Supramarginal gyrus & $\mathrm{R}$ & 48 & -20 & 31 & & 3.25 & 3.31 \\
\hline Inferior parietal lobule & $\mathrm{R}$ & 51 & -35 & 55 & & 2.23 & 2.25 \\
\hline Precuneus & $\mathrm{L}$ & -4 & -58 & 31 & 21015 & 3.16 & 3.22 \\
\hline Precuneus & $\mathrm{R} / \mathrm{L}$ & 0 & -64 & 59 & & 3.07 & 3.12 \\
\hline Precuneus/Calcarine gyrus & $\mathrm{R}$ & 2 & -65 & 21 & & 3.06 & 3.11 \\
\hline Middle frontal gyrus & $\mathrm{R}$ & 46 & 0 & 55 & 6377 & 3.00 & 3.05 \\
\hline Middle frontal gyrus & $\mathrm{R}$ & 50 & 11 & 49 & & 2.82 & 2.86 \\
\hline Middle frontal gyrus & $\mathrm{R}$ & 53 & 18 & 42 & & 2.61 & 2.64 \\
\hline Parahippocampal gyrus & $\mathrm{R}$ & 12 & 4 & -25 & 9655 & 2.86 & 2.90 \\
\hline Amygdala/hippocampus/putamen/pallidum & $\mathrm{R}$ & 29 & -3 & -10 & & 2.79 & 2.83 \\
\hline Parahippocampal gyrus & $\mathrm{R}$ & 14 & -9 & -29 & & 2.76 & 2.80 \\
\hline Thalamus & $\mathrm{L}$ & -16 & -9 & -31 & 9655 & 2.86 & 2.90 \\
\hline Putamen/amygdala & $\mathrm{L}$ & -29 & -2 & -8 & & 2.37 & 2.39 \\
\hline Pallidum & $\mathrm{L}$ & -17 & -3 & 4 & & 2.32 & 2.35 \\
\hline Rectus/superior frontal gyrus, orbital part & $\mathrm{R}$ & 12 & 32 & -13 & 2025 & 2.67 & 2.71 \\
\hline Rectus & $\mathrm{R}$ & 2 & 22 & 0 & & 2.21 & 2.23 \\
\hline NA & $\mathrm{R} / \mathrm{L}$ & 0 & 11 & -1 & & 2.14 & 2.15 \\
\hline
\end{tabular}

1 A combined threshold of $\mathrm{p}<0.05$ uncorrected and $\mathrm{k}>2817$; which equals $\mathrm{p}<0.05$ corrected for multiple comparisons across the whole brain, was employed.

thought to have a role in decision-making and evaluating the value of rewards (Kringelbach, 2005). Functional neuroimaging studies have shown that activation in the orbitofrontal cortex correlates with the value (e.g., pleasantness) of rewarding stimuli (Bartra, McGuire, \& Kable, 2013; Kringelbach, O’Doherty, Rolls, \& Andrews, 2003). The bilateral clusters in the limbic system are located subcortically and are part of the mesolimbic dopamine circuit which is involved in the motivation to eat and reward/emotion processes in general (Berridge, Ho, Richard, \& DiFeliceantonio, 2010). The hip- pocampus is well-known for its role in generating memories in general (Squire et al., 2010), and memories of certain characteristics of recently eaten foods (Higgs, 2008). The putamen and amygdala are among the regions of the brain that receive the majority of dopamine projections from the midbrain (Riccardi et al., 2006). Earlier studies showed that exposure to food results in increased dopamine levels in the dorsal striatum and that these dopamine levels correlated with the pleasantness of the food (Small, JonesGotman, \& Dagher, 2003; Volkow et al., 2002, 2003). Moreover, 

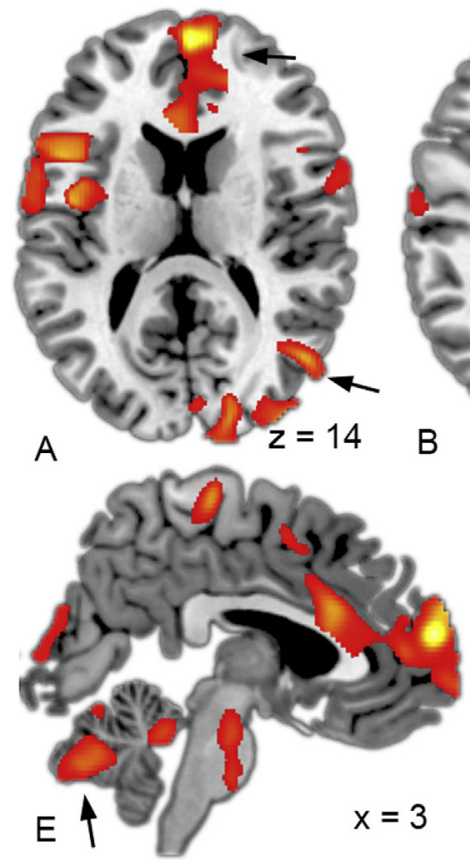
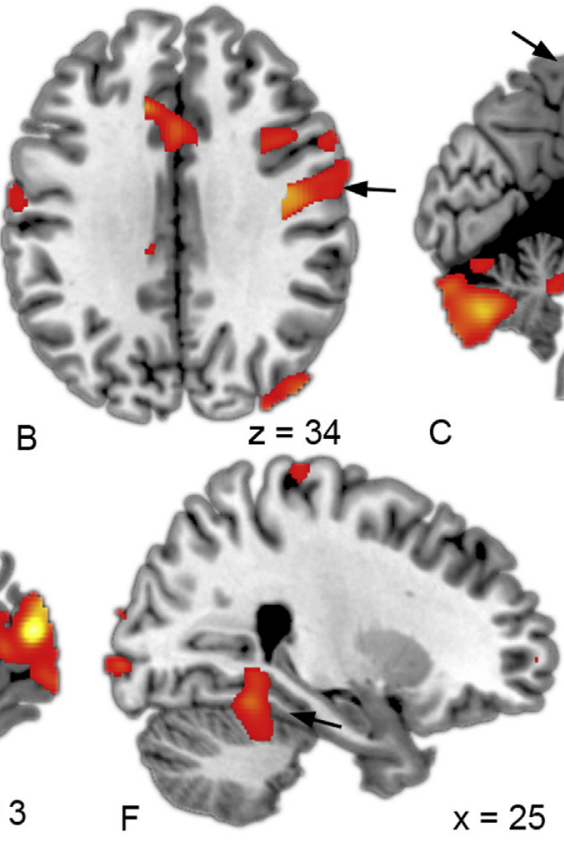
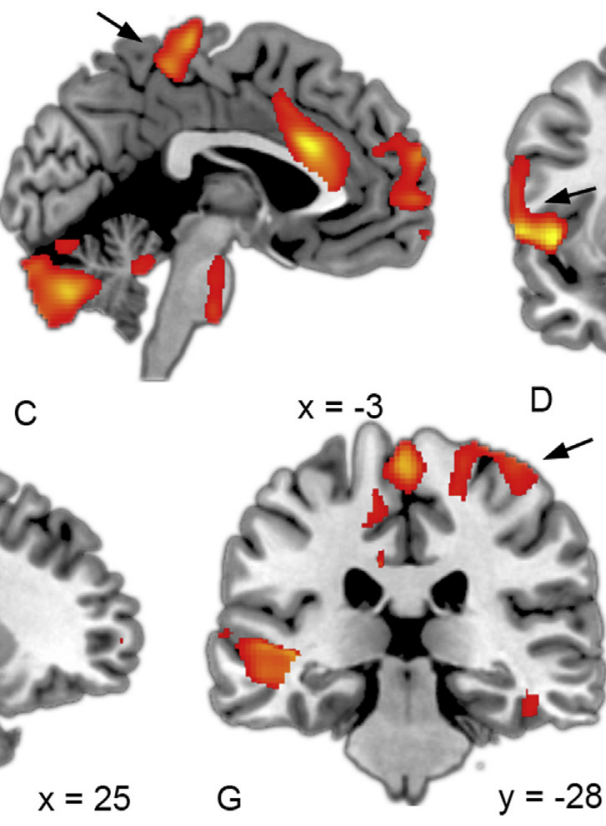

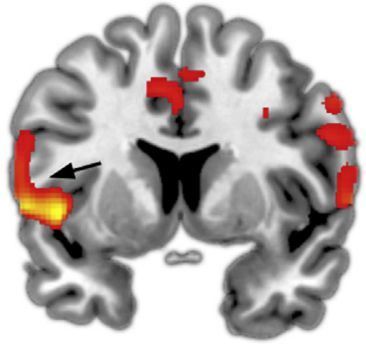

$y=8$

5

4

3

2

1

0

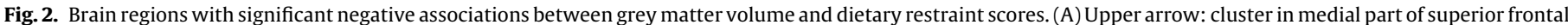

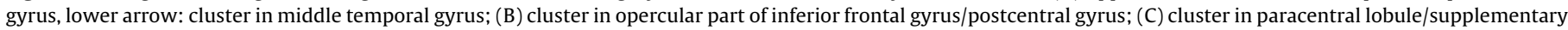

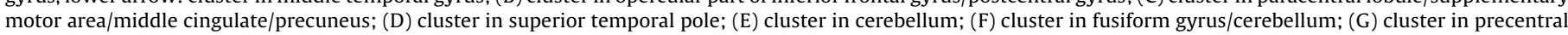
gyrus. VBM results are thresholded at $\mathrm{p}<0.05$ corrected.

Table 2

Brain regions in which regional grey matter volume was significantly ${ }^{1}$ negatively associated with restraint scores.

\begin{tabular}{|c|c|c|c|c|c|c|c|}
\hline \multirow[b]{2}{*}{ Brain region } & \multirow[b]{2}{*}{ Side } & \multicolumn{3}{|c|}{ MNI coordinates } & \multicolumn{3}{|l|}{ Cluster } \\
\hline & & $\mathrm{X}$ & $\mathrm{Y}$ & $\mathrm{Z}$ & size $\mathrm{k}$ & $\mathrm{Z}$ & $\mathrm{T}$ \\
\hline Superior frontal gyrus, medial part & $\mathrm{R}$ & 2 & 61 & 16 & 20286 & 4.48 & 4.65 \\
\hline Anterior cingulate & $\mathrm{L}$ & -1 & 21 & 26 & & 3.74 & 3.83 \\
\hline Superior frontal gyrus, medial part & $\mathrm{R}$ & 4 & 66 & 26 & & 3.26 & 3.32 \\
\hline Superior temporal pole & $\mathrm{L}$ & -57 & 13 & -2 & 176540 & 4.08 & 4.21 \\
\hline Superior temporal pole/insula & $\mathrm{L}$ & -46 & 10 & -3 & & 3.82 & 3.92 \\
\hline Rolandic operculum & $\mathrm{L}$ & -46 & -3 & 7 & & 3.75 & 3.84 \\
\hline Cerebellum & $\mathrm{L}$ & -1 & -78 & -34 & 25643 & 3.38 & 3.45 \\
\hline Middle occipital gyrus & $\mathrm{L}$ & -37 & -86 & 2 & & 3.21 & 3.27 \\
\hline Cerebellum & $\mathrm{R}$ & 7 & -69 & -31 & & 2.87 & 2.91 \\
\hline Paracentral lobule/border supplementary motor area & $\mathrm{R} / \mathrm{L}$ & 0 & -26 & 70 & 5893 & 3.26 & 3.32 \\
\hline Precuneus & $\mathrm{L}$ & -2 & -36 & 58 & & 2.93 & 2.98 \\
\hline Superior parietal lobule & $\mathrm{L}$ & -20 & -44 & 76 & & 2.38 & 2.41 \\
\hline Middle temporal gyrus & $\mathrm{R}$ & 49 & -69 & 15 & 12584 & 3.17 & 3.23 \\
\hline Cuneus & $\mathrm{R}$ & 19 & -90 & 12 & & 2.93 & 2.98 \\
\hline Cuneus & $\mathrm{R}$ & 10 & -103 & 8 & & 2.91 & 2.96 \\
\hline Postcentral gyrus/insula & $\mathrm{R}$ & 40 & -10 & 33 & 10229 & 3.06 & 3.12 \\
\hline Frontal inferior gyrus, opercular part & $\mathrm{R}$ & 58 & 15 & 29 & & 3.10 & 3.16 \\
\hline Precentral gyrus & $\mathrm{R}$ & 58 & 10 & 40 & & 2.46 & 2.49 \\
\hline Fusiform gyrus & $\mathrm{R}$ & 24 & -48 & -14 & 7320 & 2.72 & 2.76 \\
\hline Cerebellum & $\mathrm{R}$ & 6 & -45 & -23 & & 2.64 & 2.67 \\
\hline Cerebellum & $\mathrm{L}$ & -4 & -49 & -25 & & 2.14 & 2.16 \\
\hline Precentral gyrus & $\mathrm{R}$ & 19 & -22 & 64 & 2828 & 2.64 & 2.68 \\
\hline Precentral gyrus & $\mathrm{R}$ & 38 & -26 & 67 & & 2.47 & 2.50 \\
\hline Postcentral gyrus & $\mathrm{R}$ & 29 & -30 & 74 & & 2.46 & 2.49 \\
\hline
\end{tabular}

1 A combined threshold of $\mathrm{p}<0.05$ uncorrected and $\mathrm{k}>2817$; which equals $\mathrm{p}<0.05$ corrected for multiple comparisons across the whole brain, was employed.

in their 2003 PET study, Volkow et al. (2003) showed that selfreported dietary restraint was positively correlated with dopamine response to food (smelling and tasting) in the dorsal striatum. This finding is paralleled by a functional MRI study on the neural response to food pictures in restrained women by Demos et al. (2011). When highly restrained women consumed a milkshake as preload they showed greater activation in the left putamen and amygdala when viewing pictures of appetizing foods than when they consumed only water. These neuroimaging findings are in line with the well-established behavioral findings that women high in self-reported dietary restraint are more sensitive to rewarding food cues in general (Brunstrom et al., 2004; Fedoroff et al., 2003; Houben et al., 2010), and possibly even more after a dietary violation (Herman \& Mack, 1975a). Our study extends these behavioral and functional neuroimaging findings by showing that in these same areas, also more stable anatomical features, e.g., grey matter volumes, are related to the degree of restraint. This suggests that self-reported restrained eaters' increased sensitivity to food 
reward might be related to increased grey matter volume in these subcortical areas.

We also found correlations between restraint and grey matter volume in areas that are part of the somatosensory association cortex (supramarginal gyrus) and areas of the visual cortex (middle occipital gyrus, calcarine gyrus). In functional neuroimaging it is often observed that increased activation in reward-related areas (e.g., orbitofrontal cortex, ventral striatum) to rewarding stimuli (e.g, viewing pictures of appealing foods) is accompanied with increased activation in areas of the visual system (van der Laan, De Ridder, Viergever, \& Smeets, 2011). This co-activation is often interpreted by that rewarding stimuli lead to heightened activation and thereby more extensive visual processing (Killgore \& YurgelunTodd, 2007).

We found a negative correlation between self-reported dietary restraint and grey matter volume in three areas involved in inhibition, namely the dorsofrontomedial prefrontal cortex (medial part of superior frontal gyrus), the opercular part of the inferior frontal gyrus and a cluster on the border of the supplementary motor area and paracentral lobule, stretching to the middle cingulate cortex. The inferior frontal gyrus is thought to have an important role in tasks that involve response inhibition and the opercular part of the inferior frontal gyrus has previously been shown to activate during response inhibition (Aron, Robbins, \& Poldrack, 2014; Hampshire, Chamberlain, Monti, Duncan, \& Owen, 2010; Aron et al., 2014). The supplementary motor area is an intermediate link in the pathway from ventral striatum to pre-SMA, SMA to motor cortex, which is involved in the planning and execution of behavior (Haggard, 2008, 2009). The SMA and other areas in this pathway are increasingly being implicated in executive control and inhibition. It has been shown that the (pre-)SMA activates during inhibitory actions to food and nonfood stimuli (Hendrick, Luo, Zhang, \& Li, 2012; Hollmann et al., 2012; Ma et al., 2012; Pawliczek et al., 2013; Tuulari et al., 2015). Also, it has been shown that emotional stimuli can influence how the SMA influences excitability of the motor cortex (Oliveri et al., 2003). In a recent study, we found that weight-concerned subjects who are more successful in rejecting high energy snacks had increased activation in the SMA during food choice (van der Laan, De Ridder, Viergever, \& Smeets, 2014) which suggests a role of the SMA in food-related self-control. Our findings are also in line with an earlier VBM study which found that a lack of self-control and self-inhibition, as measured by a personality inventory, was related to lower grey matter volume in the SMA (Matsui et al., 2002). The significant cluster stretched from the SMA to the middle cingulate cortex which is functionally connected to the SMA and as well has been implicated to be involved the regulating of approach and avoidance behaviors (Small, Zatorre, Dagher, Evans, \& Jones-Gotman, 2001; van Rijn et al., 2015). The medial part of the superior frontal gyrus is functionally connected to the pre-SMA and is thought to exert control over pre-SMA during inhibition of (negative) emotions (Kuhn, Haggard, \& Brass, 2014). The lower grey matter volume in the medial part of the superior frontal gyrus, inferior frontal gyrus, SMA and middle cingulate found in the present study might be related to self-reported restrained eaters' reduced inhibitory capacity.

As noted, only one earlier study, by Brooks and colleagues (2011), investigated the relation between dietary restraint and regional grey matter volume. Although their null-finding might be explained by their low number of healthy control subjects $(\mathrm{n}=21)$, another difference with our study is the scale used to assess restrained eating. Brooks et al. (2011) used the Eating Disorder Examination-Questionnaire, which has its origins as assessment tool for the presence and severity of eating disorder symptoms. We used the restraint scale of the DEBQ, which has been developed to assess eating behaviors in the general population. The DEBQ is one of the most widely used restraint scales and the factor structure has been well replicated across different samples (Allison, Kalinsky, \& Gorman, 1992; Fox, Page, Peters, Armstrong, \& Kirby, 1994; Van Strien et al., 1986). The scale used to measure dietary restraint appears to be of influence: in a study that compared all measures of restraint, it was found that only the Eating Inventory Restraint Scale (Stunkard \& Messick, 1985) was predictive of successful longterm (6 months) dietary restriction (Williamson et al., 2007). The DEBQ restraint scale, amongst other widely used scales, such as the Revised Restraint Scale (Herman \& Mack, 1975b) and the Current Dieting Questionnaire (Lowe, 2015), did not show a relation with intake. DEBQ Restraint ratings might thus be more indicative of intention and perceived difficulties to resist food temptations than actual ability to restrict intake.

Since cross-sectional VBM studies only provide insight into the brain anatomy at a single point in time, it is unclear whether observed differences are a cause or consequence of dietary restraint. It might be that the observed differences in grey matter volume are predispositional factors in developing restraint. That is, that some people are born with increased grey matter volumes in the areas identified in our study which renders them more sensitive to (food) reward, and thereby increase the perceived difficulty in dealing with everyday food temptations. Although research on the relation between grey matter volumes and future (eating) behavior is scarce, at least one study supports this proposition. Yokum and colleagues (Yokum, Ng, \& Stice, 2012) found a trend that reduced grey matter volumes in regions involved in inhibition were related to increases in BMI over 1-year follow up. A second explanation could be that restrained eaters have acquired increased grey matter volume in the areas related to reward-processing as a consequence of their attempts to restrict their intake. Mild changes in grey matter volume can occur after behavioral interventions or training (Boyke, Driemeyer, Gaser, Buchel, \& May, 2008; Krafnick, Flowers, Napoliello, \& Eden, 2011; Holzel et al., 2011). States and behavior related to dieting attempts, such as weight-loss and hunger result in changes in hormones and homeostatic mechanisms which increase motivation to eat, and these effects may become stronger if people diet more frequently (Dulloo, Jacquet, Montani, \& Schutz, 2015; Dulloo et al., 2015; Hooper et al., 2010; Pietilainen, Saarni, Kaprio, \& Rissanen, 2012). An fMRI study that supports this idea is the study of Rosenbaum et al. (2008) that found that responses in areas associated with reward were higher after losing weight (compared to before weight loss. Longitudinal studies should investigate whether increased grey matter volume in reward-related areas is a predispositional factor or results from repeated periods of energy-deficit. This is important to know because it has important implications for weight-control interventions. If repeated periods of dietary restraint-related states and behaviors (e.g., temporary weight-loss, hunger) indeed result in small changes to regional grey matter volumes which predisposes people to be more reward sensitive or worse at inhibition, this would add further support to the growing body of evidence on adverse effects of dieting in lean individuals (Dulloo et al., 2015).

Although there is much evidence that the self-reported status of being a restrained eater is a marker for someone's intention rather than actual success in restricting food intake (French et al., 1994; Klesges et al., 1992; Lowe et al., 2013; Mann et al., 2007; Stice, Fisher et al., 2004; Stice et al., 2007, 2010; Tanofsky-Kraff et al., 2006; Williamson et al., 2007), it should be noted that we did not measure actual intake in our study sample. Future neuroanatomical studies should include measures of actual eating behavior to find out how grey matter volumes relate to actual success in restricting intake. Furthermore, it should be noted that we did not have independent measures of reward processing and inhibitory control in the present study. Consequently, some of our interpretations are based on reverse inference (e.g., proposing a role for reward processing because reward-related areas were identified 
in the analyses) (Poldrack, 2011), which is a limitation of our study. Therefore, an important direction for future research is to include measures of reward processing and inhibitory capacity, in addition to self-reported dietary restraint.

For interpreting restraint-related individual differences in grey matter volume, it is important to know how brain structure, i.e., regional grey matter volume, relates to brain function. Currently, the direction of volume-function relations is not entirely certain, but in the adult population there is more evidence favoring the 'higher volume - better performance' position then the 'lower volume - higher efficiency' position (DeYoung et al., 2010; Kanai \& Rees, 2011). There are many studies in adult populations that have shown that higher regional grey matter volumes are related to better functioning (for a review, see Kanai \& Rees, 2011). For example, lower grey matter volume in the inferior frontal gyrus relates to poorer performance on a task measuring inhibitory capacity (Wiers et al., 2015). Furthermore, training on particular tasks has been shown to result in increases in grey matter volume of functionally relevant areas it is possible to make mild changes in grey matter volume by behavioral interventions or training (Boyke et al., 2008; Draganski \& May, 2008; Kanai \& Rees, 2011). For example, training on a visual motor coordination task increases grey matter volume of visual motion processing area V5 (Draganski \& May, 2008). Although most studies in adults find a positive relation between regional grey matter volume and performance, there are also studies, particularly in adolescents, that found the opposite. This inverse relation is often explained by a developmental perspective: during adolescence, maturation of the cortex is accompanied by 'pruning' which means that the computational efficacy improves by the removal of weak synapses (Kanai \& Rees, 2011). Because most evidence in adults favors the higher volume - better performance position, we interpreted our results conforming to this position. However, it remains an important topic for future research to determine the exact relation between regional grey matter volume and cognitive function.

To conclude, we found that individual differences in selfreported dietary restraint are associated with regional differences in grey matter volume. Our findings that dietary restraint is related to higher regional grey matter volumes in reward-related subcortical areas and lower regional grey matter volumes in a region involved in inhibition, provide a neuroanatomical underpinning for theories that predict that self-reported dietary restraint is related to increased reward sensitivity and reduced inhibitory control capacity.

\section{Acknowledgements}

This work was funded by the European Union Seventh Framework Programma (FP7/2007-2013) under Grant Agreement 607310 (Nudge-It project). Studies of which data was used were funded by Agentschap NL (FND08009), the European Union Seventh Framework Programma (FP7/2007-2013) under Grant Agreement 266408 (Full4Health project), the European Regional Development Fund and the Dutch Provinces Gelderland and Overijssel Grant number 2011-017004 (FOCOM project), and the NWO Technology Foundation STW (grant 07438). The use of the 3T MRI facility of Wageningen University has been made possible by CAT-AgroFood (Shared Research Facilities Wageningen UR). We would like to thank professor Denise T. D. de Ridder for her valuable insights on characteristics of restrained eaters. The author contributions were as follows: LNvdL designed research; all authors conducted research; LNvdL analyzed data; LNvdL and PAM wrote paper; all authors contributed to the writing of the manuscript; LNvdL had primary responsibility for final content. All authors read and approved the final manuscript. None of the authors reported a conflict of interest related to the study.

\section{Appendix A. Supplementary data}

Supplementary data associated with this article can be found, in the online version, at http://dx.doi.org/10.1016/j.biopsycho.2016. 03.007.

\section{References}

Allison, D. B., Kalinsky, L. B., \& Gorman, B. S. (1992). A comparison of the psychometric properties of three measures of dietary restraint. Psychological Assessment, 4, 391-398.

Aron, A. R., Robbins, T. W., \& Poldrack, R. A. (2014). Inhibition and the right inferior frontal cortex: one decade on. Trends in Cognitive Sciences,

Ashburner, J. (2007). A fast diffeomorphic image registration algorithm. Neuroimage, 38, 95-113.

Ashburner, J. (2010). VBM Tutorial. Accessed 15.02.15. http://www.fil.ion.ucl.ac.uk/ john/misc/VBMclass10.pdf

Bartra, O., McGuire, J. T., \& Kable, J. W. (2013). The valuation system: a coordinate-based meta-analysis of BOLD fMRI experiments examining neural correlates of subjective value. Neuroimage, 76, 412-427.

Berridge, K. C., Ho, C. Y., Richard, J. M., \& DiFeliceantonio, A. G. (2010). The tempted brain eats: pleasure and desire circuits in obesity and eating disorders. Brain Research, 1350, 43-64.

Boyke, J., Driemeyer, J., Gaser, C., Buchel, C., \& May, A. (2008). Training-induced brain structure changes in the elderly. The Journal of neuroscience, 28 , 7031-7035.

Brooks, S. J., Barker, G. J., O’Daly, O. G., Brammer, M., Williams, S. C., Benedict, C., et al. (2011). Restraint of appetite and reduced regional brain volumes in anorexia nervosa: a voxel-based morphometric study. BMC Psychiatry, 11, 179.

Brunstrom, J. M., Yates, H. M., \& Witcomb, G. L. (2004). Dietary restraint and heightened reactivity to food. Physiology and Behavior, 81, 85-90.

Burger, K. S., \& Stice, E. (2011). Relation of dietary restraint scores to activation of reward-related brain regions in response to food intake, anticipated intake and food pictures. Neuroimage, 55, 233-239.

Cahill, L. (2006). Why sex matters for neuroscience. Nature Reviews Neuroscience, 7 477-484.

Charbonnier, L., van der Laan, L. N., Viergever, M. A., \& Smeets, P. A. (2015). Functional MRI of challenging food choices: forced choice between equally liked high- and low-calorie foods in the absence of hunger. PloS One, 10, e0131727.

Chernyak, Y., \& Lowe, M. R. (2010). Motivations for dieting: drive for thinness is different from drive for objective thinness. Journal of Abnormal Psychology, 119 276-281

Coletta, M., Platek, S., Mohamed, F. B., van Steenburgh, J. J., Green, D., \& Lowe, M. R. (2009). Brain activation in restrained and unrestrained eaters: an fMRI study. Journal of Abnormal Psychology, 118, 598-609.

Cox, R. W. (1996). AFNI: software for analysis and visualization of functional magnetic resonance neuroimages. Computers and Biomedical Research, 29, $162-173$.

DeYoung, C. G., Hirsh, J. B., Shane, M. S., Papademetris, X., Rajeevan, N., \& Gray, J. R. (2010). Testing predictions from personality neuroscience: brain structure and the big five. Psychological Science, 21, 820-828.

Demos, K. E., Kelley, W. M., \& Heatherton, T. F. (2011). Dietary restraint violations influence reward responses in nucleus accumbens and amygdala. Journal of Cognitive Neuroscience, 23, 1952-1963.

Draganski, B., \& May, A. (2008). Training-induced structural changes in the adult human brain. Behavioural Brain Research, 192, 137-142.

Dulloo, A. G., Jacquet, J., Montani, J. P., \& Schutz, Y. (2015). How dieting makes the lean fatter: from a perspective of body composition autoregulation through adipostats and proteinstats awaiting discovery. Obesity Reviews, 16(Suppl 1), 25-35.

Fedoroff, I., Polivy, J., \& Herman, C. P. (2003). The specificity of restrained versus unrestrained eaters' responses to food cues: general desire to eat, or craving for the cued food? Appetite, 41, 7-13.

Fedoroff, I. C., Polivy, J., \& Herman, C. P. (1997). The effect of pre-exposure to food cues on the eating behavior of restrained and unrestrained eaters. Appetite, 28 33-47.

Forestell, C. A., Lau, P., Gyurovski, I. I., Dickter, C. L., \& Haque, S. S. (2012). Attentional biases to foods: the effects of caloric content and cognitive restraint. Appetite, 59, 748-754.

Fox, K. R., Page, A., Peters, D. M., Armstrong, N., \& Kirby, B. (1994). Dietary restraint and fatness in early adolescent girls and boys. Journal of Adolescence, 17 , 149-161.

French, S. A., Jeffery, R. W., \& Wing, R. R. (1994). Food intake and physical activity: a comparison of three measures of dieting. Addictive Behaviors, 19, 401-409.

Fuentes, P., Barros-Loscertales, A., Bustamante, J. C., Rosell, P., Costumero, V., \& Avila, C. (2012). Individual differences in the Behavioral Inhibition System are associated with orbitofrontal cortex and precuneus gray matter volume. Cognitive, Affective, E Behavioral Neuroscience, 12, 491-498. 
Gendall, K. A., Joyce, P. R., Sullivan, P. F., \& Bulik, C. M. (1998). Food cravers: characteristics of those who binge. International Journal of Eating Disorders, 23, 353-360.

Griffioen-Roose, S., Smeets, P. A., van den Heuvel, E., Boesveldt, S., Finlayson, G., \& de, G. C. (2014). Human protein status modulates brain reward responses to food cues. The American Journal of Clinical Nutrition, 100, 113-122.

Haggard, P. (2008). Human volition: towards a neuroscience of will. Nature Reviews Neuroscience, 9, 934-946.

Haggard, P. (2009). Neuroscience. The sources of human volition. Science, 324, 731-733.

Hampshire, A., Chamberlain, S. R., Monti, M. M., Duncan, J., \& Owen, A. M. (2010). The role of the right inferior frontal gyrus: inhibition and attentional control. Neuroimage, 50, 1313-1319.

Hendrick, O. M., Luo, X., Zhang, S., \& Li, C. S. (2012). Saliency processing and obesity: a preliminary imaging study of the stop signal task. Obesity (Silver Spring), 20, 1796-1802.

Herman, C. P., \& Mack, D. (1975a). Restrained and unrestrained eating. Journal of Personality, 43, 647-660.

Herman, C. P., \& Mack, D. (1975b). Restrained and unrestrained eating. Journal of Personality, 43, 647-660.

Higgs, S. (2008). Cognitive influences on food intake: the effects of manipulating memory for recent eating. Physiology and Behavior, 94, 734-739.

Hollmann, M., Hellrung, L., Pleger, B., Schlogl, H., Kabisch, S., Stumvoll, M., et al. (2012). Neural correlates of the volitional regulation of the desire for food. International Journal of Obesity (London), 36, 648-655.

Holzel, B. K., Carmody, J., Vangel, M., Congleton, C., Yerramsetti, S. M., Gard, T., et al. (2011). Mindfulness practice leads to increases in regional brain gray matter density. Psychiatry Research, 191, 36-43.

Hooper, L. E., Foster-Schubert, K. E., Weigle, D. S., Sorensen, B., Ulrich, C. M., \& McTiernan, A. (2010). Frequent intentional weight loss is associated with higher ghrelin and lower glucose and androgen levels in postmenopausal women. Nutrition Research, 30, 163-170.

Houben, K., \& Jansen, A. (2014). Lacking skills to improve self-control: reward induced loss of control and overeating in restraint eaters. Journal of Experimental Psychopathology, 5, 29-37.

Houben, K., Roefs, A., \& Jansen, A. (2010). Guilty pleasures: implicit preferences for high calorie food in restrained eating. Appetite, 55, 18-24.

Houben, K., Roefs, A., \& Jansen, A. (2012). Guilty pleasures II: restrained eaters' implicit preferences for high: moderate and low-caloric food. Eating Behaviors, 13, 275-277.

Hu, X., Erb, M., Ackermann, H., Martin, J. A., Grodd, W., \& Reiterer, S. M. (2011). Voxel-based morphometry studies of personality: issue of statistical model specification-effect of nuisance covariates. Neuroimage, 54, 1994-2005.

Kanai, R., \& Rees, G. (2011). The structural basis of inter-individual differences in human behaviour and cognition. Nature Reviews Neuroscience, 12, 231-242.

Killgore, W. D., \& Yurgelun-Todd, D. A. (2007). Positive affect modulates activity in the visual cortex to images of high calorie foods. International Journal of Neuroscience, 117, 643-653.

Klajner, F., Herman, C. P., Polivy, J., \& Chhabra, R. (1981). Human obesity, dieting: and anticipatory salivation to food. Physiology and Behavior, 27, 195-198.

Klesges, R. C., Isbell, T. R., \& Klesges, L. M. (1992). Relationship between dietary restraint, energy intake, physical activity: and body weight: a prospective analysis. J. Abnormal Psychology, 101, 668-674.

Knight, L. J., \& Boland, F. J. (1989). Restrained eating: an experimental disentanglement of the disinhibiting variables of perceived calories and food type. Journal of Abnormal Psychology, 98, 412-420.

Krafnick, A. J., Flowers, D. L., Napoliello, E. M., \& Eden, G. F. (2011). Gray matter volume changes following reading intervention in dyslexic children. Neuroimage, 57, 733-741.

Kringelbach, M. L. (2005). The human orbitofrontal cortex: linking reward to hedonic experience. Nature Reviews Neuroscience, 6, 691-702.

Kringelbach, M. L., O’Doherty, J., Rolls, E. T., \& Andrews, C. (2003). Activation of the human orbitofrontal cortex to a liquid food stimulus is correlated with its subjective pleasantness. Cerebral Cortex, 13, 1064-1071.

Kuhn, S., Haggard, P., \& Brass, M. (2014). Differences between endogenous and exogenous emotion inhibition in the human brain. Brain Structure and Function, 219, 1129-1138.

Laessle, R. G., Tuschl, R. J., Kotthaus, B. C., \& Pirke, K. M. (1989). A comparison of the validity of three scales for the assessment of dietary restraint. Journal Abnormal Psychology, 98, 504-507.

LeGoff, D. B., \& Spigelman, M. N. (1987). Salivary response to olfactory food stimuli as a function of dietary restraint and body weight. Appetite, 8, 29-35.

Lowe, M. R. (1993). The effects of dieting on eating behavior: a three-factor model Psychological Bullettin, 114, 100-121.

Lowe, M. R. (2015). The effects of dieting on eating behavior: a three-factor model. Psychological Bulletin, 114, 100-114

Lowe, M. R., Doshi, S. D., Katterman, S. N., \& Feig, E. H. (2013). Dieting and restrained eating as prospective predictors of weight gain. Frontier Psychology, 4, 577

Lowe, M. R., \& Levine, A. S. (2005). Eating motives and the controversy over dieting: eating less than needed versus less than wanted. Obesity Research, 13, 797-806.

Luders, E., Gaser, C., Narr, K. L., \& Toga, A. W. (2009). Why sex matters: brain size independent differences in gray matter distributions between men and women. The Journal of Neuroscience, 29, 14265-14270.

Ma, J., Lei, D., Jin, X., Du, X., Jiang, F., Li, F., et al. (2012). Compensatory brain activation in children with attention deficit/hyperactivity disorder during a simplified Go/No-go task. Journal of Neural Transmission, 119, 613-619.
Mann, T., Tomiyama, A. J., Westling, E., Lew, A. M., Samuels, B., \& Chatman, J. (2007). Medicare's search for effective obesity treatments: diets are not the answer. American Psychology, 62, 220-233.

Matsui, M., Yoneyama, E., Sumiyoshi, T., Noguchi, K., Nohara, S., Suzuki, M., et al. (2002). Lack of self-control as assessed by a personality inventory is related to reduced volume of supplementary motor area. Psychiatry Research, 116, 53-61.

Meule, A., Lukito, S., Vogele, C., \& Kubler, A. (2011). Enhanced behavioral inhibition in restrained eaters. Eating Behaviour, 12, 152-155.

Nederkoorn, C., Van Eijs, Y., \& Jansen, A. (2004). Restrained eaters act on impulse. Personality and Individual Differences, 37, 1651-1658.

Neumark-Sztainer, D., Sherwood, N. E., French, S. A., \& Jeffery, R. W. (1999). Weight control behaviors among adult men and women: cause for concern? Obesity Research, 7, 179-188.

Oliveri, M., Babiloni, C., Filippi, M. M., Caltagirone, C., Babiloni, F., Cicinelli, P., et al. (2003). Influence of the supplementary motor area on primary motor cortex excitability during movements triggered by neutral or emotionally unpleasant visual cues. Experimental Brain Research, 149, 214-221

Papies, E. K., \& Hamstra, P. (2010). Goal priming and eating behavior: enhancing self-regulation by environmental cues. Health Psychology, 29, 384-388.

Papies, E. K., Stroebe, W., \& Aarts, H. (2007). Pleasure in the mind: restrained eating and spontaneous hedonic thought about food. Journal of Experimental and Social Psychology, 43, 810-817.

Papies, E. K., Stroebe, W., \& Aarts, H. (2008). The allure of forbidden food: on the role of attention in self-regulation. Journal of Experimental and Social Psychology, 44, 1283-1292.

Pawliczek, C. M., Derntl, B., Kellermann, T., Kohn, N., Gur, R. C., \& Habel, U. (2013) Inhibitory control and trait aggression: neural and behavioral insights using the emotional stop signal task. Neuroimage, 79, 264-274.

Pietilainen, K. H., Saarni, S. E., Kaprio, J., \& Rissanen, A. (2012). Does dieting make you fat? A twin study. International Journal of Obesity (London), 36, 456-464.

Pingitore, R., Spring, B., \& Garfield, D. (1997). Gender differences in body satisfaction. Obesity Research, 5, 402-409.

Poldrack, R. A. (2011). Inferring mental states from neuroimaging data: from reverse inference to large-scale decoding. Neuron, 72, 692-697.

Polivy, J., Coleman, J., \& Herman, C. P. (2005). The effect of deprivation on food cravings and eating behavior in restrained and unrestrained eaters. International Journal of Eating Disorders, 38, 301-309.

Polivy, J., Heatherton, T. F., \& Herman, C. P. (1988). Self-esteem, restraint and eating behavior. Journal of Abnormal Psychology, 97, 354-356.

Riccardi, P., Li, R., Ansari, M. S., Zald, D., Park, S., Dawant, B., et al. (2006). Amphetamine-induced displacement of [18F] fallypride in striatum and extrastriatal regions in humans. Neuropsychopharmacology, 31, 1016-1026.

de Ridder, D., Adriaanse, M., Evers, C., \& Verkes, R. J. (2014). Who diets? Most people and especially when they worry about food. Appetite, 80, 103-108.

Rosenbaum, M., Sy, M., Pavlovich, K., Leibel, R. L., \& Hirsch, J. (2008). Leptin reverses weight loss-induced changes in regional neural activity responses to visual food stimuli. The Journal of Clinical Investigation, 118, 2583-2591.

Small, D. M., Jones-Gotman, M., \& Dagher, A. (2003). Feeding-induced dopamine release in dorsal striatum correlates with meal pleasantness ratings in healthy human volunteers. Neuroimage, 19, 1709-1715.

Small, D. M., Zatorre, R. J., Dagher, A., Evans, A. C., \& Jones-Gotman, M. (2001) Changes in brain activity related to eating chocolate: from pleasure to aversion. Brain, 124, 1720-1733.

Smeets, P. A., Kroese, F. M., Evers, C., \& De Ridder, D. T. (2013). Allured or alarmed: counteractive control responses to food temptations in the brain. Behavioural Brain Research, 248, 41-45.

Squire, L. R., van der Horst, A. S., McDuff, S. G., Frascino, J. C., Hopkins, R. O., \& Mauldin, K. N. (2010). Role of the hippocampus in remembering the past and imagining the future. Proceedings of the National Academy of Sciences of the United States of America, 107, 19044-19048.

Stice, E., Cooper, J. A., Schoeller, D. A., Tappe, K., \& Lowe, M. R. (2007). Are dietary restraint scales valid measures of moderate- to long-term dietary restriction?: Objective biological and behavioral data suggest not. Psychological Assessment, 19, 449-458.

Stice, E., Fisher, M., \& Lowe, M. R. (2004). Are dietary restraint scales valid measures of acute dietary restriction? Unobtrusive observational data suggest not. Psychological Assessment, 16, 51-59.

Stice, E., Presnell, K., Shaw, H., \& Rohde, P. (2004). Psychological and behavioral risk factors for obesity onset in adolescent girls: a prospective study. Journal of Consulting and Clinical Psychology, 73, 195-202.

Stice, E., Sysko, R., Roberto, C. A., \& Allison, S. (2010). Are dietary restraint scales valid measures of dietary restriction?: Additional objective behavioral and biological data suggest not. Appetite, 54, 331-339.

Stonnington, C. M., Tan, G., Kloppel, S., Chu, C., Draganski, B., Jack, C. R., Jr., et al. (2008). Interpreting scan data acquired from multiple scanners: a study with Alzheimer's disease. Neuroimage, 39, 1180-1185.

Stunkard, A. J., \& Messick, S. (1985). The three-factor eating questionnaire to measure dietary restraint: disinhibition and hunger. Journal of Psychosomatic Research., 29, 71-83.

Taki, Y., Kinomura, S., Sato, K., Inoue, K., Goto, R., Okada, K., et al. (2008). Relationship between body mass index and gray matter volume in 1428 healthy individuals. Obesity (Silver Spring), 16, 119-124.

Tanofsky-Kraff, M., Cohen, M. L., Yanovski, S. Z., Cox, C., Theim, K. R., Keil, M., et al. (2006). A prospective study of psychological predictors of body fat gain among children at high risk for adult obesity. Pediatrics, 117, 1203-1209. 
Tuulari, J. J., Karlsson, H. K., Hirvonen, J., Salminen, P., Nuutila, P., \& Nummenmaa, L. (2015). Neural circuits for cognitive appetite control in healthy and obese individuals: an fMRI study. PloS One, 10, e0116640.

van der Laan, L. N., De Ridder, D. T., Charbonnier, L., Viergever, M. A., \& Smeets, P. A. (2014). Sweet lies: neural, visual, and behavioral measures reveal a lack of self-control conflict during food choice in weight-concerned women. Frontiers in Behavioral Neuroscience, 8, 184.

van der Laan, L. N., De Ridder, D. T., Viergever, M. A., \& Smeets, P. A. (2014). Activation in inhibitory brain regions during food choice correlates with temptation strength and self-regulatory success in weight-concerned women. Frontiers in Neuroscience, 8, 308.

van der Laan, L. N., De Ridder, D. T., Viergever, M. A., \& Smeets, P. A. (2011). The first taste is always with the eyes: a meta-analysis on the neural correlates of processing visual food cues. Neuroimage, 55, 296-303.

van der Laan, L. N., De Ridder, D. T., Viergever, M. A., \& Smeets, P. A. (2012). Appearance matters: neural correlates of food choice and packaging aesthetics. PloS One, 7, e41738.

van Rijn, I., de Graaf, C., \& Smeets, P. A. (2015). Tasting calories differentially affects brain activation during hunger and satiety. Behavioural Brain Research, 279, 139-147.

Van Strien, T. (2000). Ice-cream consumption, tendency toward overeating and personality. International Journal of Eating Disorders, 28, 460-464.

Van Strien, T., Frijters, J. E. R., Bergers, G. P. A., \& Defares, P. B. (1986). The Dutch eating behavior questionnaire (DEBQ) for assessment of restrained, emotional: and external eating behavior. International Journal of Eating Disorders, 5. 195-215.

Veit, R., Kullmann, S., Heni, M., Haring, H. U., Fritsche, A., \& Preissl, H. (2014). Reduced cortical thickness associated with visceral fat and BMI. Neuroimage Clinical, 6, 307-311.
Volkow, N. D., Wang, G. J., Fowler, J. S., Logan, J., Jayne, M., Franceschi, D., et al. (2002). Nonhedonic food motivation in humans involves dopamine in the dorsal striatum and methylphenidate amplifies this effect. Synapse, 44 175-180.

Volkow, N. D., Wang, G. J., Maynard, L., Jayne, M., Fowler, J. S., Zhu, W., et al. (2003) Brain dopamine is associated with eating behaviors in humans. International Journal of Eating Disorders, 33, 136-142.

Wagner, D. D., Boswell, R. G., Kelley, W. M., \& Heatherton, T. F. (2012). Inducing negative affect increases the reward value of appetizing foods in dieters. Journal of Cognitive Neuroscience, 24, 1625-1633.

Werthmann, J., Roefs, A., Nederkoorn, C., Mogg, K., Bradley, B. P., \& Jansen, A (2013). Attention bias for food is independent of restraint in healthy weight individuals-an eye tracking study. Eating Behaviour, 14, 397-400.

Wiers, C. E., Gawron, C. K., Gropper, S., Spengler, S., Stuke, H., Lindenmeyer, J., et al. (2015). Decreased gray matter volume in inferior frontal gyrus is related to stop-signal task performance in alcohol-dependent patients. Psychiatry Research, 233, 125-130.

Williamson, D. A., Martin, C. K., York-Crowe, E., Anton, S. D., Redman, L. M., Han, H., et al. (2007). Measurement of dietary restraint: validity tests of four questionnaires. Appetite, 48, 183-192.

de Witt Huberts, J. C., Evers, C., \& De Ridder, D. T. (2013). Double trouble: restrained eaters do not eat less and feel worse. Psychology E Health, 28, 686-700.

Yokum, S., Ng, J., \& Stice, E. (2012). Relation of regional gray and white matter volumes to current BMI and future increases in BMI: a prospective MRI study. International Journal of Obesity (London), 36, 656-664. 